\title{
The Release of Copper, Manganese, and Iron from Complexed Acrylamide-Sodium Acrylate Hydrogels
}

\author{
Nadia A. Rizk*, Bothaina M. Abd El-Hady, Salwa El- \\ Sabbagh and E.S. El-Safy \\ Department of Polymers and Pigments, National Research \\ Centre, Dokki, Giza, Egypt.
}

YDROGELS based on acrylamide and sodium acrylate have
been prepared by the chemical initiation and gamma radiation
methods. The chemical method was used in presence of ammonium
persulfate at $30{ }^{\circ} \mathrm{C}$, whereas, the gamma irradiation method was used
in presence of triethanolamine at $1 \mathrm{KGy}$. The complexed hydrogels
were tested for the adsorption of metal ions, e.g. $\left(\mathrm{Cu}^{2+}, \mathrm{Mn}^{2+}, \mathrm{Fe}^{2+}\right)$.
Factors affecting metal ions adsorption by the gel namely, metal ion
concentrations, and time of immersion were studied. The physical
properties of the complexed gel namely $\mathrm{U} . \mathrm{V}$. -reflectance, X-ray
diffraction, together with its thermal stability were studied. The
scanning electron micrographs showed that the hydrogel has a great
ability to adsorb metal ions in the following order $\mathrm{Mn}^{2+}>\mathrm{Cu}^{2+}>\mathrm{Fe}^{2+}$.
Release of metals from the complexed gel was investigated. Results
showed that, the hydrogel prepared by gamma radiation has a greater
tendency towards metal adsorption than the one prepared by
chemical initiation. Keywords: Release of metal, Complexed hydrogel and Metal adsorption.

Hydrogels may be considered as the most interesting polymeric materials that find wide applications in many fields. They are used in bioengineering, biomedicine, pharmaceutical, veterinary, food industry, agriculture, and others. It is used as controlled release systems of drugs, for the production of contact lenses, as adsorbents for removal of some agents in environmental applications and as carrier matter, pesticides and fertilizer in agriculture ${ }^{(1-7)}$.

Several methods have been attempted to remove heavy metal ions, such as ion exchange, membrane separation, reverse osmosis, chemical precipitation, and adsorption ${ }^{(8-11)}$. The adsorption technology has been proved to be one of the most effective and economic ways due to its easiness to operate and simplicity to design ${ }^{(12-15)}$. The main advantages of hydrogel-based adsorbents are easy loading capturing of cations with simple chemicals in most cases ${ }^{(16)}$.

\footnotetext{
*Correspondent Author: E-mail:nrizk43@yahoo.com
} 
A variety of polymer adsorbents have been investigated for copper adsorption, including polymer fibers and nano-composites ${ }^{(17-20)}$. Hydrogelsbased sorbents functionalized with amino, hydroxyl, carboxyl, imidazole, and hydrazine groups were reported to demonstrate high capacities in the removal of metal ions from aqueous solutions due to their complexing abilities ${ }^{(16,21,22)}$. Ning et al. synthesize a high-strength hydrogel which can adsorb $\mathrm{Cu}^{2+}$ ions effectively and be used repeatedly without loss in adsorption capacity and mechanical property. For this purpose they synthesized 2-vinyl-4, 6-diamino1,3,5 triazine / oligo (ethylene glycol) methacrylate copolymer hydrogel by photo polymerization. The mechanical strength of hydrogels was tested and adsorption of $\mathrm{Cu}^{2+}$ ions onto the hydrogels under different conditions was investigated. Furthermore, the reusable property of the hydrogels was evaluated by repeated adsorption ${ }^{(23)}$.

Recently, Chen et al. studied the adsorption capacity and kinetic of copper adsorption on poly (N-isopropyl acrylamide) hydrogel by the incorporation of acrylic acid, an anionic comonomer as copper chelating group ${ }^{(24)}$. Chan Van Miuh et al. studied the swelling of polyacrylamide hydrogels which depends on the nature of introduced transition metal ions $\mathrm{Cu}(\mathrm{II}), \mathrm{Mn}(\mathrm{II}), \mathrm{Zn}(\mathrm{II}), \mathrm{Cr}$ (II), $\mathrm{Ni}(\mathrm{II})$ and $\mathrm{Fe}(\mathrm{II})^{(25)}$.

Mita et al. determined the total water content in synthetic transition metal hydroxide hydrogels by heat treatment at $700{ }^{0} \mathrm{C}$ for $2 \mathrm{hr}{ }^{(26)}$. Siyam et al. studied the interaction of polyacrylic acid (PAA) and acrylic acid-acrylamide copolymer (PAA-Am) with copper sulphate to evaluate the thermal and radiation chemical stabilities of the resultant polymers ${ }^{(27)}$. Jingjing Wang et al. prepared ion imprinted hydrogel with interpenetrating network structure and studied its application to adsorb $\mathrm{Cu}$ (II) ions from aqueous solution. They found that the adsorption capacity of $\mathrm{Cu}$ (II) increased with the initial $\mathrm{pH}$ value of the solution, but decreased as the temperature rose from 303 to $323 \mathrm{k}^{\text {(28) }}$.

In this study, hydrogels of acrylamide-sodium acrylate crosslinked with ethanolamines were prepared by free radical polymerization and gamma radiation ${ }^{(29)}$. The prepared hydrogels were complexed with different concentrations of metal ions of $\mathrm{Cu}^{2+}, \mathrm{Mn}^{2+}$, and $\mathrm{Fe}^{2+}$. The release of metals from complexed hydrogels was investigated.

\section{Materials}

\section{Experimental}

The principal monomer used was acrylamide (Am). Acrylamide monomer was initiated using ammonium persulphate (Merck). Triethanolamine (TEA), a product of Merck was used as a crosslinker. Mineral salts, Copper sulphate (ADWIA), Manganese sulphate (LTD) and Ferrous sulphate (BDH) were used. 


\section{Techniques}

Preparation of hydrogels

Hydrogels were prepared by copolymerization of acrylamide (Am) with sodium acrylate $(\mathrm{NaA})$ in presence of triethanolamine (TEA) as a crosslinking agent by gamma radiation at a dose rate $8.8 \mathrm{~Gy} / \mathrm{h}$. Another sample was prepared in aqueous solution in presence of ammonium persulphate at $30{ }^{\circ} \mathrm{C}$ for $1.5 \mathrm{hr}$ in presence of oxygen. The ratio of acrylamide to sodium acrylate monomer was 70:30. Irradiation process was carried out using the gamma cell of the National Center for Radiation Research and Technology, Nasr City, Cairo, Egypt. The formed hydrogels were washed thoroughly with distilled water several times and finally dried in vacuum oven at $50{ }^{\circ} \mathrm{C}$.

\section{Metal salt solutions}

Different concentrations of $\mathrm{CuSO}_{4}, \mathrm{MnSO}_{4}$ and $\mathrm{FeSO}_{4}$ solutions $(0.01,0.02$, $0.04,0.05$ and $0.1 \mathrm{M}$ ) were prepared. AmNaATEA was soaked for $24 \mathrm{hr}$ in solutions of metal salts. The samples were removed from the solutions and dried in an oven at $50{ }^{\circ} \mathrm{C}$. Release of metal ions from complexed hydrogels was determined spectrophotometically using spectrophotometer technique (UV2401PC) ${ }^{(30)}$.

\section{Characterization}

Determination of water uptake

After extracting the soluble part, a certain weight $\left(\mathrm{W}_{1}\right)$ of the hydrogel was placed in a beaker containing distilled water for $24 \mathrm{hr}$ at room temperature. The sample was removed from the beaker and blotted with a filter paper just to remove the droplets of water on the surface. The water uptake of the sample was calculated using the following equation:

$$
\text { Water-uptake, } \%=\left(\left(\mathrm{W}_{2}-\mathrm{W}_{1}\right) / \mathrm{W}_{1}\right) \times 100
$$

where $\mathrm{W}_{1}$ : is the initial weight of hydrogel.

$$
\mathrm{W}_{2} \text { : is the final weight of swelled hydrogel. }
$$

\section{$U V$-reflectance}

UV-reflectance spectra of the prepared hydrogel complexed with metal was carried out using UV-VIS-NIR spectrophotometer Shimadza at the Central Laboratory of Services, National Research Center, Cairo, Egypt.

\section{$X$-ray diffraction}

The X-ray diffraction patterns of prepared hydrogels were measured by a Shimadza Diffractometer XD-DI series at the National Center for Radiation Research and Technology, Nasr City, Cairo, Egypt, which is operating automatically. The X-ray copper target tube was operated at $40 \mathrm{kV}$ and $30 \mathrm{~mA}$. All the diffraction patterns speed of $20 \mathrm{~mm} / \mathrm{min}$. 
Thermal analysis (TGA)

Thermogravimetric analysis (TGA) of the hydrogel was carried out using the Perkin-Elmer analyzer, USA. The sample weighing between 13 and $25 \mathrm{mg}$ were scanned from 50 to $1000{ }^{\circ} \mathrm{C}$ using a nitrogen air flow of $50 \mathrm{ml} / \mathrm{min}$ and a heating rate of $10{ }^{\circ} \mathrm{C} / \mathrm{min}$.

\section{Scanning Electron Microscope}

The photographs of hydrogel samples were carried out using scanning microscope of the type Japan Jeol (JXA- 840 A) Electron Probe Micro Analyzer.

\section{Results and Discussion}

In this study, acrylamide-sodium acrylate copolymers crosslinked with triethanolamine at $1 \mathrm{KGy}$ with water uptake 202.01 (g water/g gel) after $24 \mathrm{hr}$, were taken as an example of a hydrogel prepared by gamma radiation.

Acrylamide-sodium acrylate copolymers crosslinked with triethanolamine in presence of $\mathrm{O}_{2}$ with water uptake 435.1 (g water/ g gel) after $24 \mathrm{hr}$, were used as an example of a hydrogel prepared by free radical polymerization.

The prepared hydrogel was complexed with $\mathrm{Cu}^{2+}, \mathrm{Mn}^{2+}$, and $\mathrm{Fe}^{2+}$ ions by immersing the dried hydrogel in a water solution of $\mathrm{CuSO}_{4}, \mathrm{MnSO}_{4}$, and $\mathrm{FeSO}_{4}$. The effect of metal ion concentrations and time of immersion on the adsorption of metal by hydrogel was studied.

\section{Effect of metal ion concentrations}

Figures $1 \& 2$ showed the effect of different metal ion concentrations on the capacity of AmNaATEA hydrogel (prepared at $1 \mathrm{KGy}$ and in presence of $\mathrm{O}_{2}$ ). It was observed that the tendency of adsorption of metals followed the order $\mathrm{Mn}^{2+}>\mathrm{Cu}^{2+}>\mathrm{Fe}^{2+}$ ions. Hydrogels prepared by gamma radiation adsorbed the metal ions greater than those prepared by free radical polymerization.

\section{Effect of time}

Tables $1 \& 2$ show that on increasing time of immersion the ability of the hydrogel (prepared at $1 \mathrm{KGy}$ and in presence of $\mathrm{O}_{2}$ ) to adsorb metal ions increases.

\section{Swelling}

The swelling of the dried complexed hydrogel with metal ions in distilled water was shown in Fig 3. It was found that on increasing the metal ion concentrations the gel swells to a lower extent. 


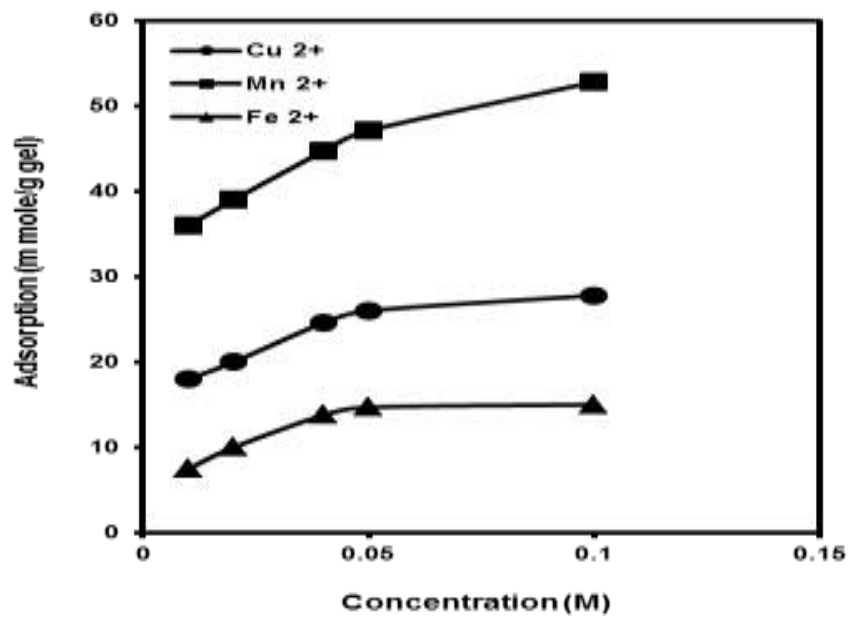

Fig. 1. Effect of metal ion concentrations on the adsorption of AmNaATEA hydrogel at $1 \mathrm{KGy}$.

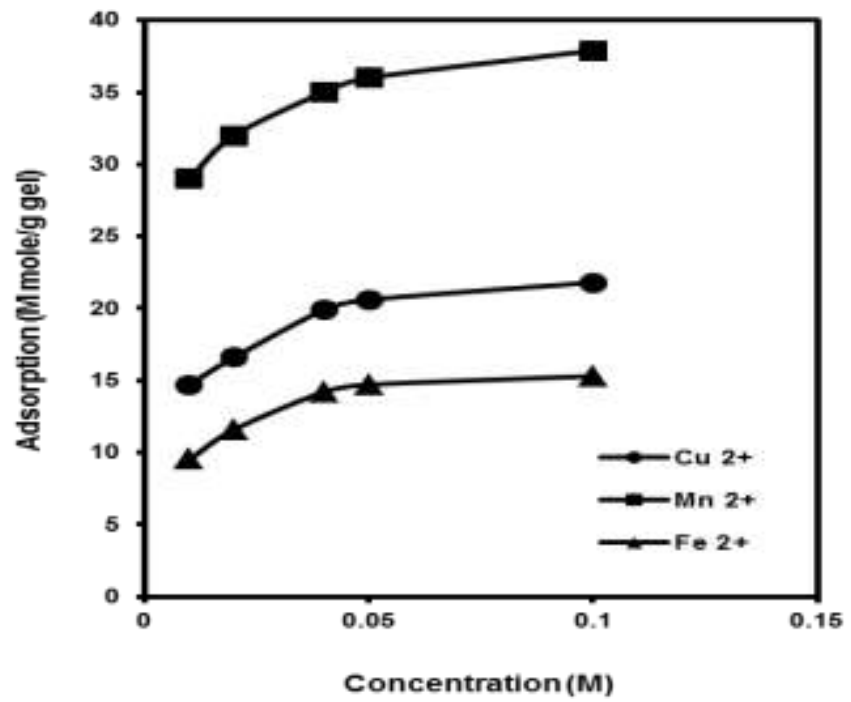

Fig.2. Effect of metal ion concentrations on the adsorption of AmNaATEA hydrogel in presence of $\mathrm{O}_{2}$. 
TABLE 1. Effect of time on adsorption of metal ions by AmNaATEA hydrogel (prepared at 1 KGy).

\begin{tabular}{|c|c|c|c|c|c|}
\hline \multirow{2}{*}{$\begin{array}{c}\text { Metal ion } \\
\text { concentration } \\
(\mathbf{M})\end{array}$} & \multicolumn{5}{|c|}{ Adsorption (m mole/ g gel) } \\
\cline { 2 - 6 } & $\mathbf{1 ~ h r}$ & $\mathbf{3 ~ h r}$ & $\mathbf{5} \mathbf{~ h r}$ & $\mathbf{1 2} \mathbf{~ h r}$ & $\mathbf{1 6} \mathbf{~ h r}$ \\
\hline $\mathrm{Cu}^{2+}$ & 11.2415 & 12.41 & 13.52 & 14.9921 & 16.2152 \\
\hline $\mathrm{Mn}^{2+}$ & 22.15 & 26.91 & 29.3311 & 34.51 & 35.44 \\
\hline $\mathrm{Fe}^{2+}$ & 5.9 & 6.21 & 6.68 & 7.20 & 7.20 \\
\hline
\end{tabular}

TABLE 2. Effect of time on adsorption of metal ions by AmNaATEA hydrogel (prepared in presence of $\mathrm{O}_{2}$ ).

\begin{tabular}{|c|c|c|c|c|c|}
\hline \multirow{2}{*}{$\begin{array}{c}\text { Metal ion } \\
\text { concentration } \\
(\mathbf{M})\end{array}$} & \multicolumn{5}{|c|}{ Adsorption (m mole/ g gel) } \\
\cline { 2 - 6 } & $\mathbf{1} \mathbf{h r}$ & $\mathbf{3} \mathbf{~ h r}$ & $\mathbf{5} \mathbf{h r}$ & $\mathbf{1 2} \mathbf{~ h r}$ & $\mathbf{1 6} \mathbf{~ h r}$ \\
\hline $\mathrm{Cu}^{2+}$ & 7.8215 & 9.321 & 10.522 & 12.2151 & 13.1213 \\
\hline $\mathrm{Mn}^{2+}$ & 12.758 & 16.322 & 18.5152 & 23.2532 & 26.5321 \\
\hline $\mathrm{Fe}^{2+}$ & 3.2342 & 5.2142 & 6.6752 & 7.2715 & 8.6954 \\
\hline
\end{tabular}

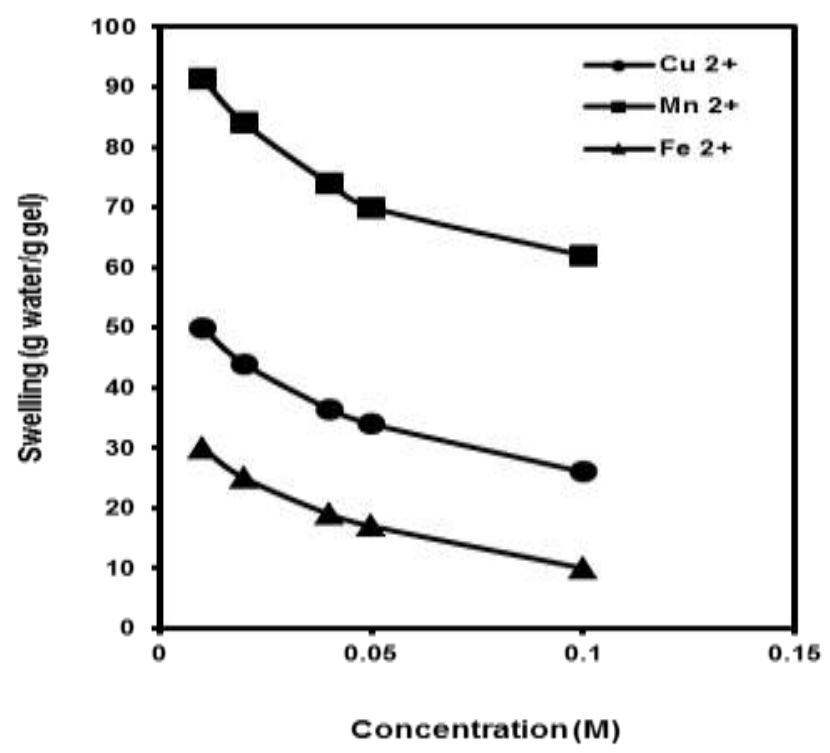

Fig. 3. Swelling of adsorbed metal ion hydrogels in distilled water . 
Effect of different salt concentrations on the degree of swelling of complexed hydrogels

Since the soil contains different types of salts, therefore, it is of interest to study the effect of changing salt concentrations on the swelling behavior of hydrogels.

\section{Effect of $\mathrm{NaCl}$ solution}

The study of the swelling of the complexed gel in sodium chloride was shown in Fig. 4. It was observed that the swelling of the complexed gel decreases with the increase of $\mathrm{NaCl}$. This decrease is due to the presence of salt in water which facilitates the possibility of the interaction between the polymer molecules and the cations or anions of the salt that might break the hydrogen bonds between water molecules and the hydrophilic charged sites of the polymer.

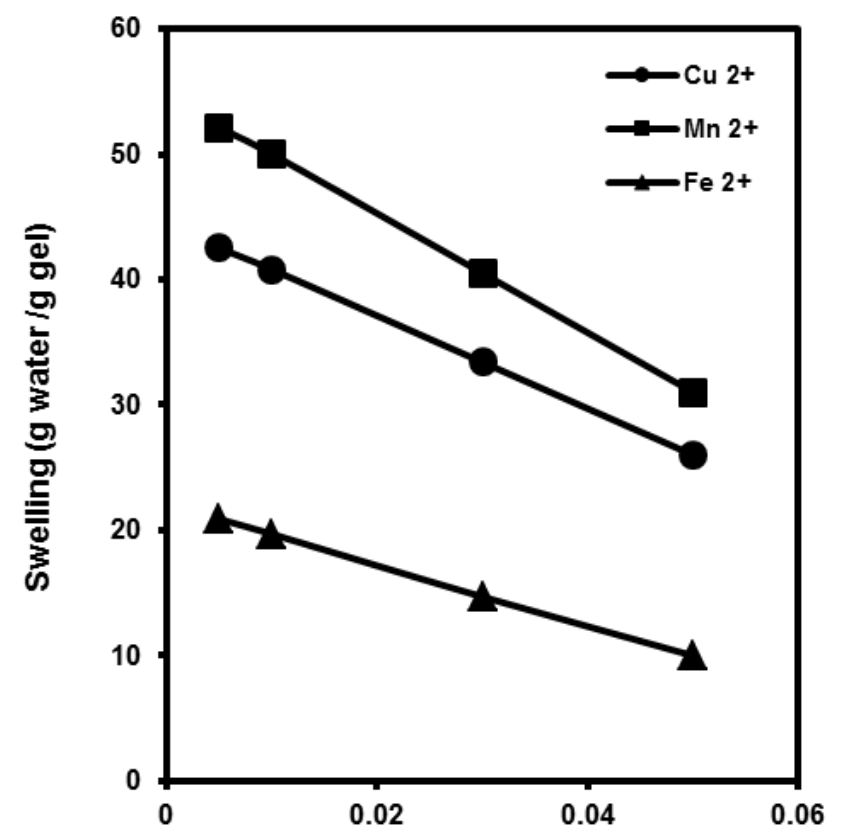

\section{Concentration(mole/l)}

Fig. 4. Effect of $\mathrm{NaCl}$ concentration on the swellability of adsorbed metal ion hydrogels. 
Effect of different salt solutions

The swelling of the complexed gels was studied in presence of different salt solutions $\left(\mathrm{NaCl}, \mathrm{CaCl}_{2}, \mathrm{MgCl}_{2}\right)$. Figure 5 shows that the ability of the hydrogel complexed with $\mathrm{Cu}^{2+}$ ions to swell decreases following the order $\mathrm{CaCl}_{2}>\mathrm{MgCl}_{2}>\mathrm{NaCl}$, i.e. swelling hydrogels in presence of divalent salts shows a lower decrease than in monovalent ones.

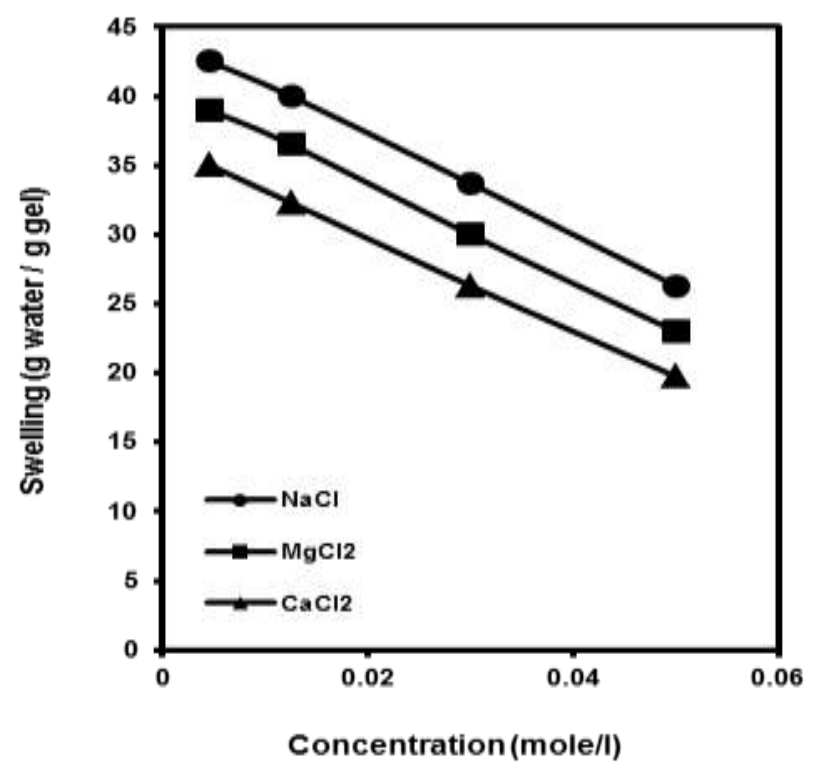

Fig. 5. Effect of different saline solutions on the swellability of adsorbed $\mathrm{Cu}^{2+}$ hydrogels.

Release

The study of the release of metal ions from the complexed gel was investigated by means of the spectrophotometer technique. Figures $6 \& 7$ show that the release of metal ions at different time intervals followed the order $\mathrm{Mn}^{2+}>\mathrm{Cu}^{2+}>\mathrm{Fe}^{2+}$ ions. The release of metal ions from the complexed hydrogel prepared by gamma radiation is greater than those prepared by free radical polymerization.

\section{$U V$-reflectance}

The electronic spectra for the prepared AmNaATEA hydrogel before and after complexing with $\mathrm{CuSO}_{4}$ were shown in Fig. 8\&9. The characteristic peaks at 228-269 $\mathrm{nm}$ are due to $\mathrm{n}-\Pi^{*}$ transition of $\mathrm{C}=\mathrm{O}$ groups present and the peak at $850 \mathrm{~nm}$ due to presence of metal ion. This peak disappeared as represented from the spectra of the non-complexed gel (Fig. 9). 


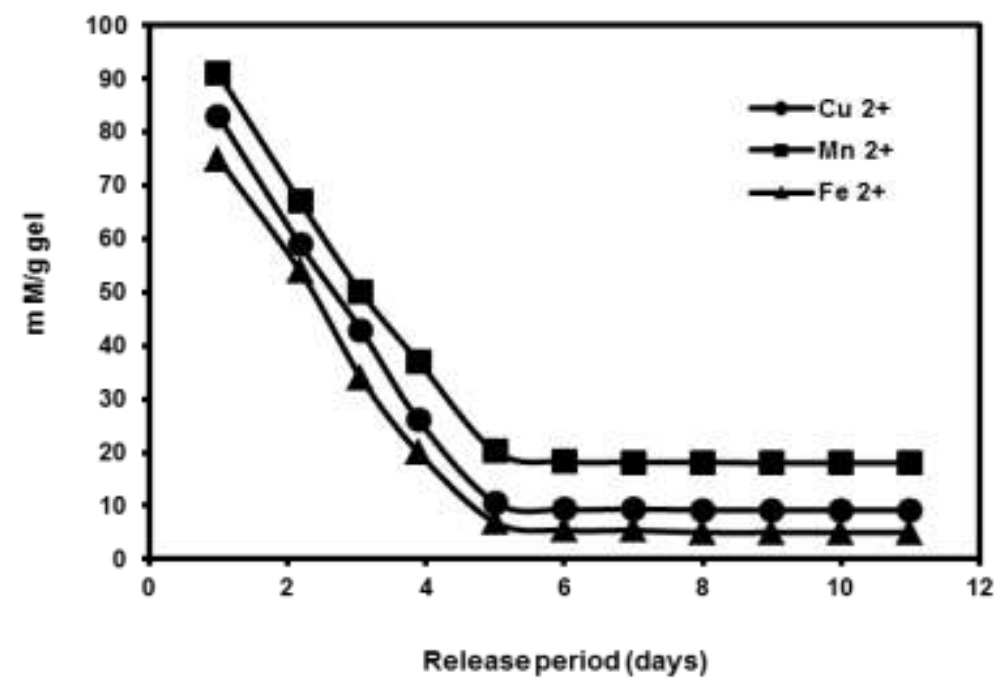

Fig. 6. The release of metal ions after different time period ( days) from hydrogels ( prepared by free radical polymerization).

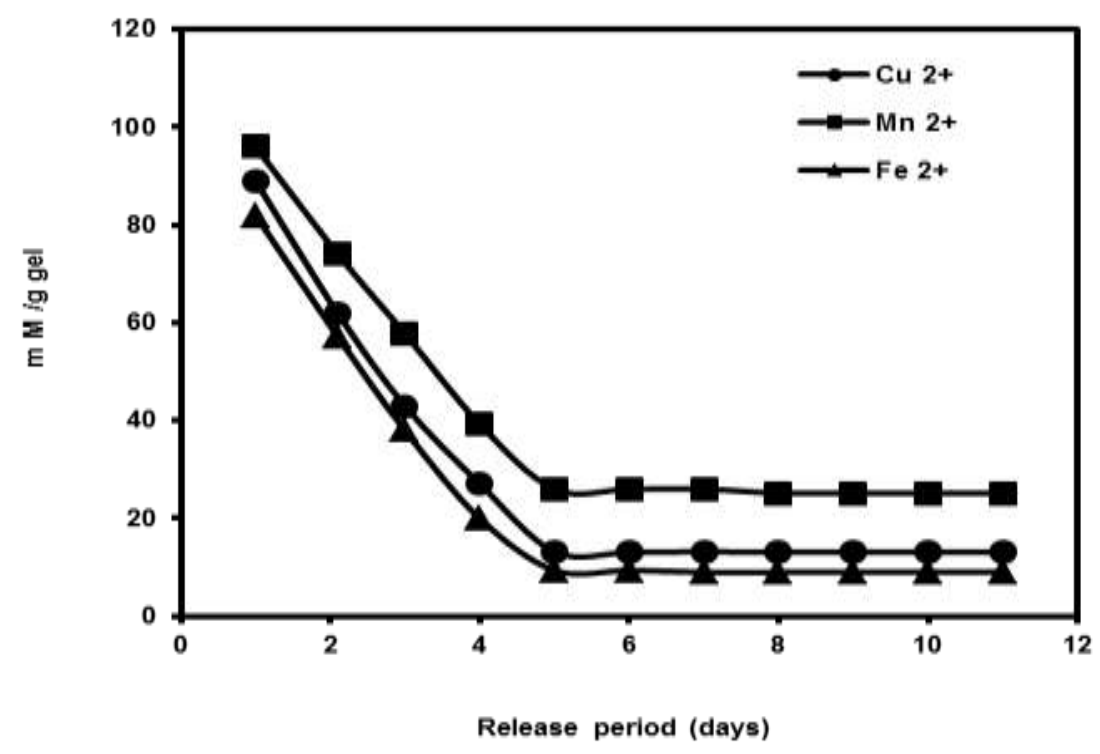

Fig. 7. The release of metal ions after different time period ( days) from hydrogels ( prepared at 4 KGry). 


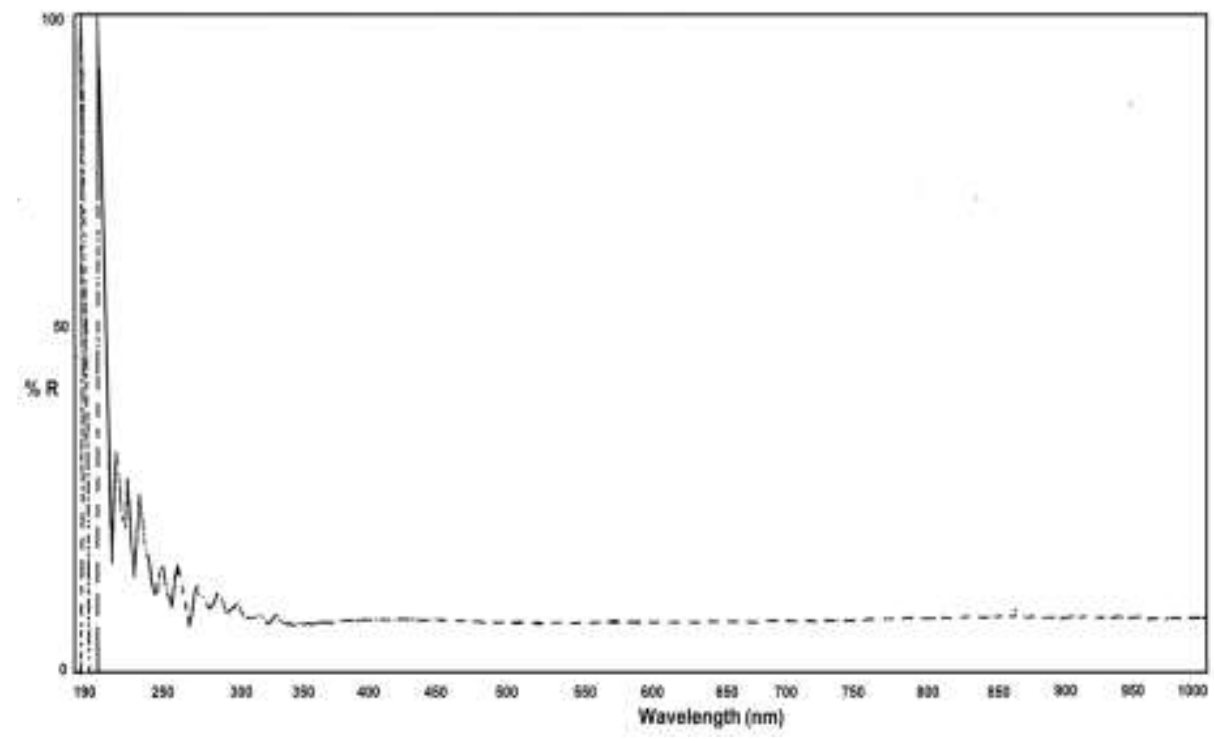

Fig. 8. Electronic spectrum of AmNaATEA hydrogel .

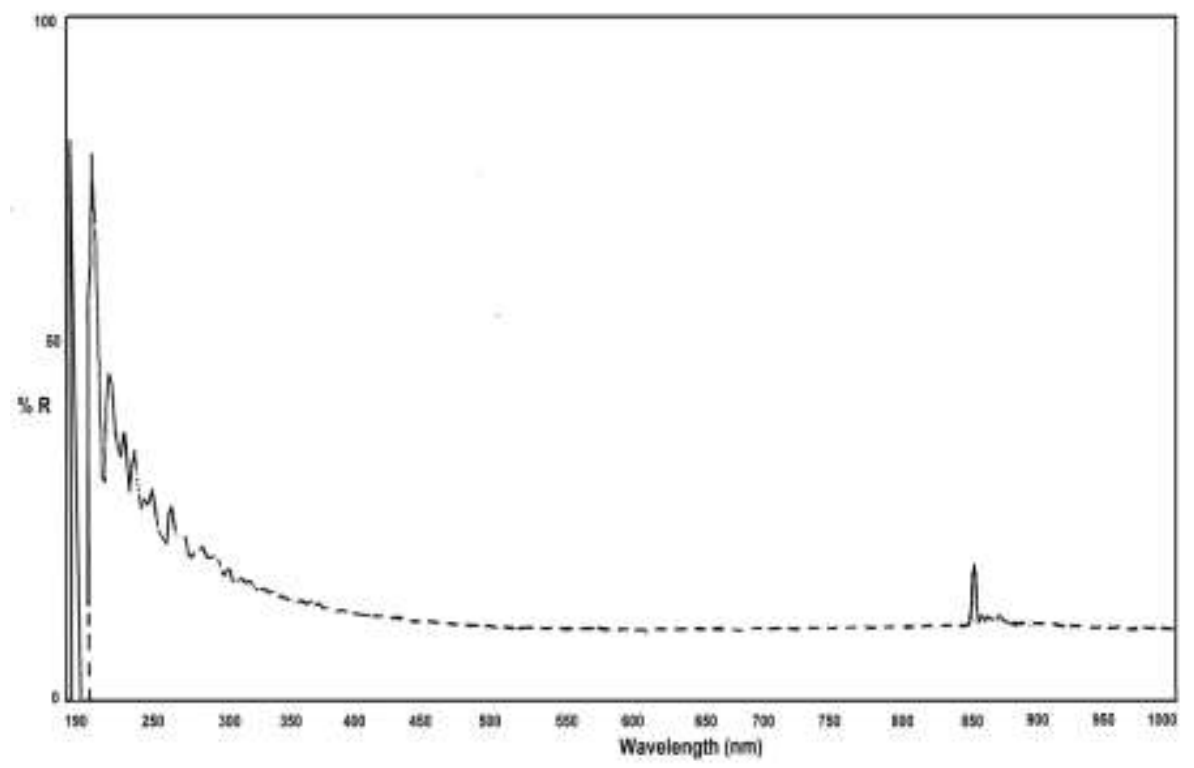

Fig. 9. Electronic spectrum of AmNaATEA hydrogel complexed with $\mathrm{CuSO}_{4}$. 


\section{$X$-ray diffraction}

X-ray diffraction data of the two hydrogels (prepared at $1 \mathrm{KGy}$ and in the presence of $\left.\mathrm{O}_{2}\right)$ before and after adsorption of metal ions $\left(\mathrm{Cu}^{2+}, \mathrm{Mn}^{2+}\right.$, and $\left.\mathrm{Fe}^{2+}\right)$ were shown in Tables $3 \& 4$. This technique was used to represent their morphological structure and the change in their crystal form, which is due to the effect of adsorption of metal ions. The interplanar distances of the hydrogel adsorbed $\mathrm{Mn}^{2+}$ ions were $17.52 \mathrm{~A}^{0}$ and $16.70 \mathrm{~A}^{0}$ as illustrated in Tables $3 \& 4$, which is greater than other complexed gels by about three times. The high interplanar distance is attributed to the formation of new crosslinked polymeric chains, which are, formed from the interplanar hydrogen bonding between the chains.

It was found that the integrated intensity (counts) is taken as an indication of the amorphous and crystallinity percent of the hydrogel. When the integrated intensity (counts) was increased, the crystallinity was also increased.

It was concluded that the hydrogel complexed with $\mathrm{Mn}^{2+}$ ions was an amorphous one ${ }^{(9)}$, while that complexed with $\mathrm{Cu}^{2+}$ and $\mathrm{Fe}^{2+}$ ions was found to be crystalline.

TABLE 3. X-ray diffraction measurements of AmNaATEA hydrogel (prepared at $1 \mathrm{KGy}$ ) before and after adsorption of metal ions.

\begin{tabular}{|c|c|c|}
\hline Sample & $\mathbf{d}\left(\mathbf{A}^{\mathbf{0}}\right)$ & Integrated intensity (counts) \\
\hline Blank & 5.7869 & 298 \\
\hline $\mathrm{a}$ & 6.0545 & 735 \\
\hline $\mathrm{b}$ & 17.521 & 187 \\
\hline $\mathrm{c}$ & 6.1545 & 541 \\
\hline
\end{tabular}

TABLE 4. X-ray diffraction measurements of AmNaATEA hydrogel (prepared in presence of $\mathrm{O}_{2}$ ) before and after adsorption of metal ions.

\begin{tabular}{|c|c|c|}
\hline Sample & $\mathbf{d}\left(\mathbf{A}^{\mathbf{0}}\right)$ & Integrated intensity (counts) \\
\hline Blank & 5.7869 & 298 \\
\hline $\mathrm{a}$ & 6.0545 & 735 \\
\hline $\mathrm{b}$ & 16.7002 & 187 \\
\hline $\mathrm{c}$ & 6.1545 & 541 \\
\hline
\end{tabular}

$T G A$

The thermogravimetric analysis (TGA) is used to investigate both the thermal decomposition as well as the thermal stability of polymers. The TGA thermogram of AmNaATEA hydrogel (prepared at 1KGy), (Fig. 10) shows that the thermal decomposition of the hydrogel occurs in two steps. In the first step, the hydrogel loses about $34.55 \%$ of its weight, in the second step $88.89 \%$ in the vicinity of $500^{\circ} \mathrm{C}$, i.e. the weight of the hydrogel after decomposition was about $11.1 \%$. The TGA of AmNaATEA hydrogel after adsorption of $\mathrm{Cu}^{2+}$ ions (Fig. 11) shows that the thermal decomposition of the complexed hydrogel takes place in four steps.

Egypt. J. Chem. 58, No.5 (2015) 
In the first step, the complexed hydrogel loses about $32.74 \%$ of its weight, $38.85 \%$ in the second step, $57.84 \%$ in the third step, and $92.21 \%$ in the fourth step in the vicinity of $700^{\circ} \mathrm{C}$. The weight of the hydrogel remaining at $500^{\circ} \mathrm{C}$ was about $16.4 \%$. The remaining weight of hydrogel adsorbed $\mathrm{Cu}^{2+}$ ions is greater than hydrogel alone, i.e. the hydrogel complexed with $\mathrm{Cu}^{2+}$ increases the stability of the hydrogel.

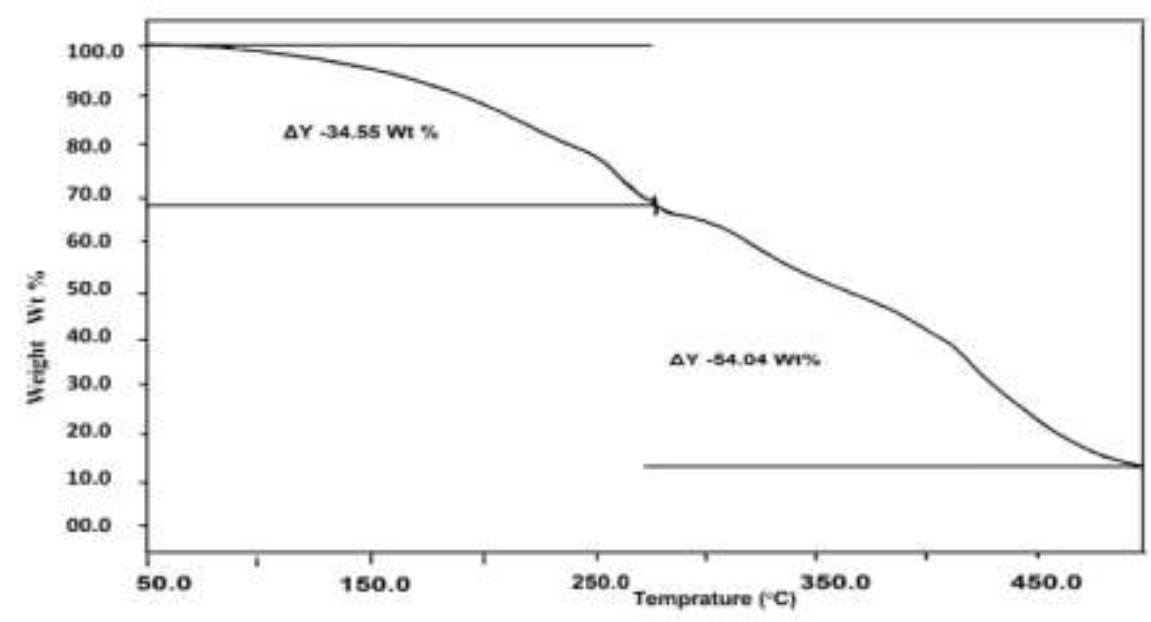

Fig. 10. TGA diagram for AmNaATEA hydrogel prepared at 1KGy.

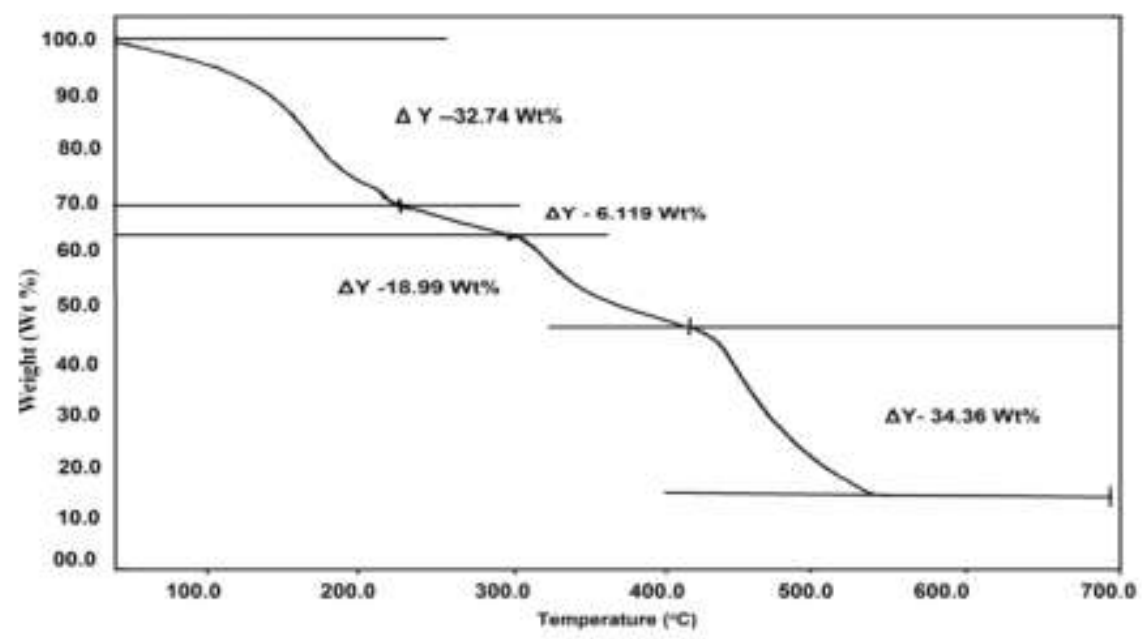

Fig. 11.TGA diagram for AmNaATEA hydrogel complexed with $\mathrm{CuSO}_{4}$. 
Scanning electron microscope (SEM)

Figure 12 (A) shows SEM micrographs of the fracture surfaces of the AmNaATEA (the pure hydrogel), it was found that the surface is not smooth; it is full of irregularity, many holes and cavities. On the other hand, the SEM micrograph of the complexed gel with $\mathrm{Cu}^{2+}$ ions in Fig. 12 (B) shows copper ions dispersed on the surface of the hydrogel in the crystal structure. The $\mathrm{Fe}^{2+}$ ions can be seen on the surface but in small quantities in Fig 12 (D). While Fig. 12 (C) shows large quantities of $\mathrm{Mn}^{2+}$ ions dispersed on the surface of the gel. The SEM micrographs give further support to the results of metal uptake and to the respective affinity of the hydrogel for the different metals under investigation.

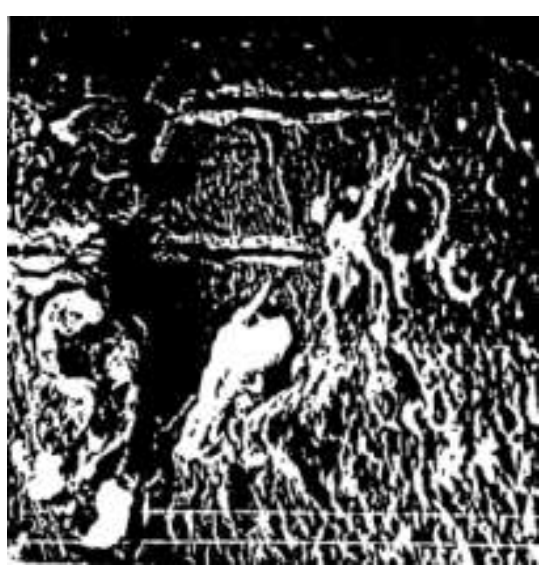

(A)

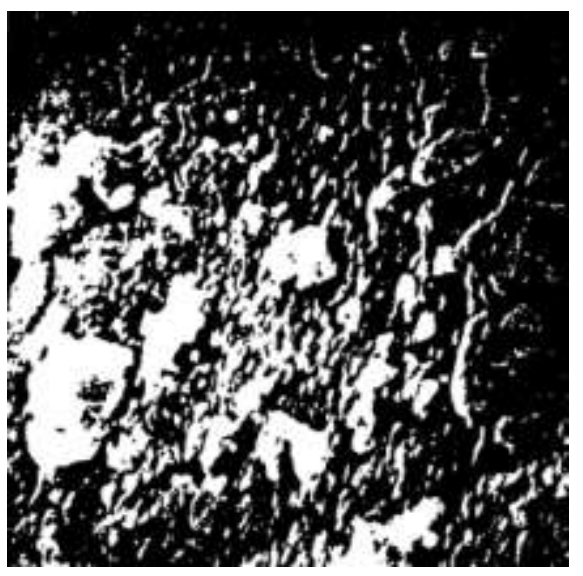

(C)

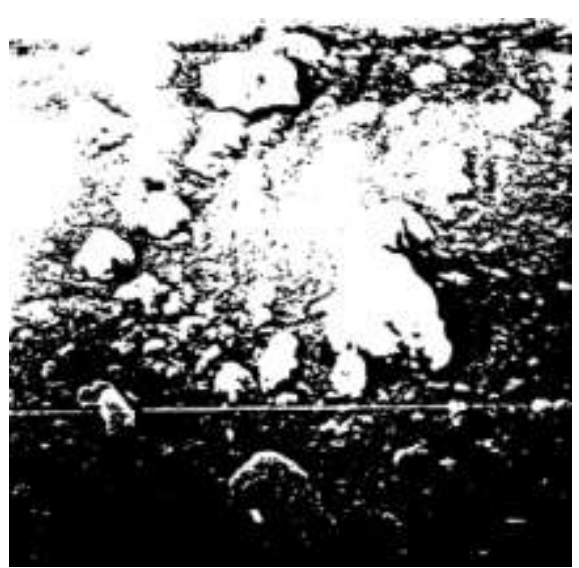

(B)

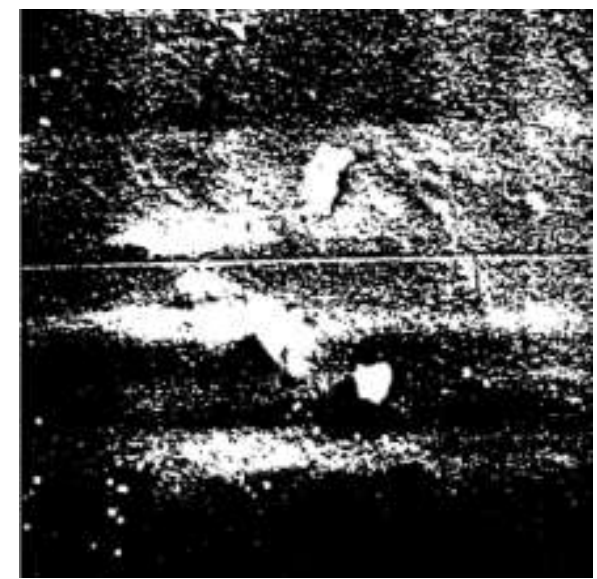

(D)

Fig. 12. SEM images of (A) AmNaATEA hydrogel, (B) AmNaATEA hydrogel complex with $\mathrm{CuSO}_{4},(\mathrm{C})$ AmNaATEA hydrogel complex with $\mathrm{MnSO}_{4}$, and (D) AmNaATEA hydrogel complex with $\mathrm{FeSO}_{4}$ at magnification 1000x.

Egypt. J. Chem. 58, No.5 (2015) 


\section{Conclusions}

The hydrogels of AmNaA copolymers crosslinked with TEA gave the highest values of water uptake, the swellability of the hydrogels decreases with the increase of the concentrations of the crosslinker and irradiation doses. The TGA thermogram of AmNaADEA hydrogel was found to be more stable than those of AmNaAMEA and AmNaATEA hydrogels ${ }^{(29)}$. The ability of the prepared hydrogels to absorb water decreases with the increase of salt concentrations.

\section{References}

1. Kost, R. Langer, Hydrogel Medicine and Pharmacy, ed. Peppas NA 3, 95, CRC Press, Florida (1987).

2. Saraydine, E. Karadag, Oztop, H.N. and Guven, O., Biomaterials, 15, 917 (1994).

3. Saraydine, E. Karadag and Guven, O., Polym. Adv. Technol. 6, 719-26 (1995).

4. Saraydine, E. Karadag and Guven, O., Sep. Sci. Technol. 31, 423 (1996).

5. Oztop, H.N., Saraydine, E. Karadag and Guven, O., Polym. Bull. 40, 575 (1998).

6. Saraydine, E. Karadag, Cetinkaya, Z. and Guven, O., Biomaterials, 17, 67 (1996).

7. Saraydine, E. Karadag and Guven, O., Polym. Bull. 36, 745 (1996).

8. Basso, M.C., Cerrella, E.G. and Cakierman, A.L., Ind. Eng. Chem. Res. 41, 180189(2002).

9. Gomez-Salazar, S., Lee, J.S., Heydweille, J.C. and Tavlarides, L.L.S., Ind. Eng. Chem. Res. 42, 3403-3412 (2003).

10. Huang, C.P., Chumg, Y.C. and Liou, M.R., J. Hazard. Mater. 45, 265-277 (1996).

11. Monier, M., Ayad, D.M. and Sarhan, A.A., J. Hazard. Mater. 176, 348-355 (2010).

12. Veli, S. and Alyuz, B., J. Hazard. Matr. 149, 226-233 (2007).

13. Cheung, C.W., Porter, J.F. and McKay, G., Langmuir ,18, 650-656 (2002).

14. Lam, K.F., Chen, X., Fong, C.M. and Yeung, K.L., Chem. Commun. 17, 20342036 (2008).

15. Manu, V., Mody, H.M., Bajaj, H.C. and Jasra, R.V., Ind. Eng. Chem. Res. 48, 8954-8960 (2009).

16. Kasgoz, H., Ozgnmus, S. and Oraby, M., Polymer, 44, 1785-1793 (2003). 
17. Kampalanonwat, P. and Supaphol, P., ACS. Appl. Mater Interface, 2, 3619-3627 (2010).

18. Deng, S.B., Bai, R.B. and Chen, J.P., Langmuir,19 5058-5064 (2003).

19. Chen, L.F., Liang, H.W., Cui, Y. tu. cH. and Yu, S.H., Langmuir, 27, 8998-9004 (2011).

20. Hu. J., Lo, L. MC. and Chen, G.H., Langmuir, 21, 11173-11179 (2005).

21. Bekiart, V., Sotiropoulou, M., Bokias, G. and Lianos, P., Colloids Surf. A 312 214-218 (2008).

22. Ali, A.E., Shawky, H.A., Rehim, H.A.A.R.E. and Hegazy, E.A., Eur. Polym. J. 39, 2337-2344 (2003).

23. Ning, W., Yanjiao, H., Yuan, L., Tao, B., Han, G., Peng, Z., Wei, W. and Wenguang, L., J. of Hazardous Materials , 213-214, 258-264 (2012).

24. Chen, J.J., Ahmad, A.L. and Ooi, B.S., J. of Envi. Chem. Eng. 1, 339-348 (2013).

25. Chanvan Miuh, Astania, NA.N. and Rudenko, A., Pvestn. Mosk. Univ. Zikhim, 35(4), 367-74 (Russ) (1994).

26. Mita, N.K., Berejee, A., Mukhejee P. and Basumjemdar, A.J., Indian Chem. Soc. 63(20), 1071-3 (1986).

27. Ashour, Siyam T. and Yousef, H.A., Polym. Int. 48, 799-804 (1999).

28. Jingjing, W., Laing, D., Jun, W. and Fang, L., App. Surface Sci. $305412-418$ (2014).

29. Rizk, Nadia A., Abd El-Hady Bothaina M. and El-Safy, E.S., Egypt. J. Appl. Sci. 18(6B) (2003).

30. Pieh, S.H. and El-Hady, O.A., J. Soil Sci. 30 (1-2), 159-67 (1990).

(Received 26/4/2015; accepted $2 / 8 / 2015$ ) 


\title{
إفراز النحاس- المنجنيز و الحديد من متراكبات هلاميات الأكريلاميد صوديوم أكريلات
}

\author{
ناديـة عبد القـادر رزق ، بثينة محمد عبد الهـادى ، سلـوى الصباغ

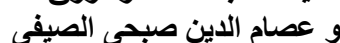 \\ قسم البلمرات و المخضبات - المركز القومى للبحوث - الدقى - الجيزة - مصر .
}

تم تحضير هلاميات الأكريلاميد و صوديوم أكريلات بواسطة التنشيط الكيميائى

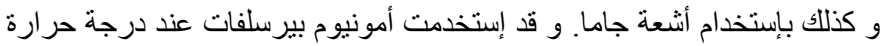

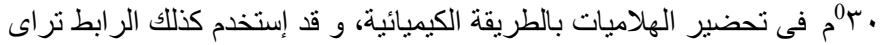

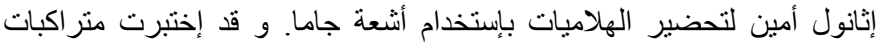

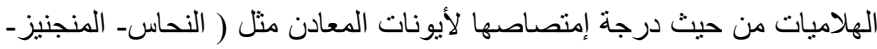

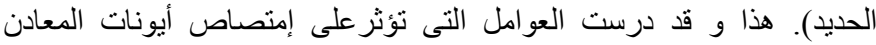

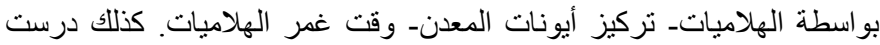

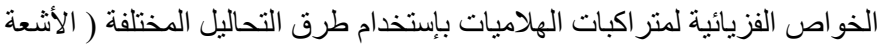

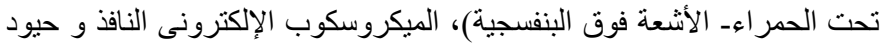

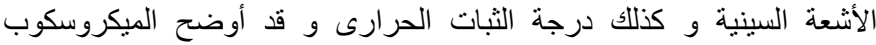

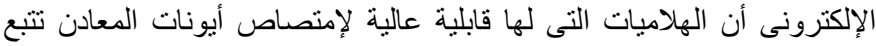

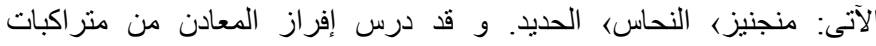

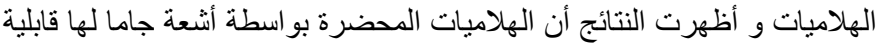
عالية لإمتصاص أيونات المعادن عن المحضرة بو اسطة التنشيط الكيميائى. 
The Release of Copper, Manganese, and Iron ... 